\title{
The dilemma of healthy eating and environmental sustainability: the case of fish
}

\author{
Angie Clonan ${ }^{1, *}$, Michelle Holdsworth ${ }^{2}$, Judy A Swift ${ }^{1}$, Didier Leibovici ${ }^{3}$ and \\ Paul Wilson ${ }^{1,4}$ \\ 'Division of Nutritional Sciences, School of Biosciences, University of Nottingham, Loughborough LE12 5RD, UK: \\ ${ }^{2}$ UMR NUTRIPASS, Institute of Research for Development, UM1, UM2, Supagro, Montpellier, France: ${ }^{3}$ Centre for \\ Geospatial Science, University of Nottingham, Nottingham, UK: ${ }^{4}$ Division of Agricultural and Environmental \\ Sciences, School of Biosciences, University of Nottingham, Loughborough, UK
}

Submitted 20 May 2010: Accepted 24 March 2011: First published online 24 May 2011

\begin{abstract}
Objective: Despite widespread concern over exploitation of the European Union's fish stocks, dietary guidelines in the UK continue to recommend two portions of fish per week. The present study sought to investigate whether health and/or sustainability are motivating factors when purchasing and consuming fish and whether there are sociodemographic trends.

Design: A structured, self-completion postal questionnaire exploring consumers' attitudes towards purchasing fish, their dietary intake, stated purchasing behaviour and sociodemographic information.

Setting: Nottinghamshire, UK.

Subjects: Adults from 842 households randomly selected from the electoral register. Results: Over half of the participants $(57 \cdot 0 \%)$ were aware of the health benefits of fish consumption and reported health as a primary motivator for purchasing fish; however, only $26 \cdot 8 \%$ actively sought to purchase fish from a sustainable source (e.g. Marine Stewardship Council (MSC) certified fish). Only 30.6\% of participants met current dietary recommendations for fish intake. Older respondents ( $>60$ years of age) were more likely to report purchasing fish for health reasons and to buy MSC fish. Participants were significantly less likely to report MSC purchases if they agreed with the statement 'I am confused about which type of fish I should be eating to protect fish stocks' $(P<0 \cdot 001)$.

Conclusions: The number of consumers purchasing fish for health reasons was more than those seeking sustainably sourced fish; yet, they still failed to meet the recommended intake set by the Food Standards Agency. Dietary advice to the public to increase consumption of fish conflicts with the prevailing pressure on fish stocks. Clear advice should be communicated enabling consumers to meet nutritional needs while protecting fish stocks.
\end{abstract}

UK dietary guidelines continue to recommend the consumption of at least two portions of fish per week, one of which should be oily ${ }^{(1)}$, as regular fish consumption is associated with decreased risk of several health problems including $\mathrm{CVD}^{(2)}$ and cancer ${ }^{(3)}$. The beneficial effect of fish consumption, especially that of oily fish, is derived from omega-3 ( $n-3)$ fatty acids - in particular from the bioactive properties of EPA and DHA, both long-chain PUFA (LCPUFA) present only in the $n-3$ fats from marine sources. Although man can endogenously convert EPA and DHA from alternative sources of $n-3$ fatty acids, such as seeds, nuts and tofu ${ }^{(4)}$, it is not a particularly efficient process $^{(5)}$. Fish, therefore, remains the predominant and most readily available source of $n-3$ fatty acids. Fish also has the advantage of being low in saturated fat, yet high in protein and Se, making it a healthy alternative to meat ${ }^{(6)}$. A recent review by the World Cancer Research Fund ${ }^{(7)}$ advocates reducing the intake of red meat in the diet and partly replacing it with poultry or 'all types of fish'; heeding such advice could place further demands on fish stocks.

If the UK population is to achieve the Food Standards Agency's (FSA) recommendation for fish intake of two $140 \mathrm{~g}$ portions per week ${ }^{(8)}$, current consumption will need to be increased from the average of $1 \cdot 2$ portions per week reported in the most recent National Diet and Nutrition survey data ${ }^{(9)}$. This would increase the demand on fish stocks in the European Union (EU) and around the world, which are already under pressure ${ }^{(10)}$; some estimates suggest that fish stocks of over three-quarters of 
Table 1 Guidelines for consumers on sustainability of tuna fish (adapted from guidelines provided by the Marine Conservation Society ${ }^{(16)}$ )

\begin{tabular}{|c|c|c|c|}
\hline Species & Eat & Caution & Avoid \\
\hline Tuna, Albacore & MSC certified & $\begin{array}{l}\text { From North Pacific; pole and } \\
\text { line from North Atlantic }\end{array}$ & $\begin{array}{l}\text { Longline and pelagic, trawled from } \\
\text { the Mediterranean region and } \\
\text { from the North and South } \\
\text { Atlantic }\end{array}$ \\
\hline Tuna, Bigeye & $-t$ & $\begin{array}{l}\text { Handline and pole and line } \\
\text { from Central and Western } \\
\text { Pacific }\end{array}$ & All other stocks \\
\hline Tuna, Bluefin & $-t$ & $-t$ & $-\dagger$ \\
\hline Tuna, Skipjack & $\begin{array}{l}\text { Pole and line from the Western } \\
\text { and Central Pacific or from } \\
\text { the Maldives }\end{array}$ & $\begin{array}{l}\text { Purse seine from the Indian } \\
\text { Ocean or from the Eastern } \\
\text { Pacific }\end{array}$ & $\begin{array}{l}\text { Purse seine from the Western } \\
\text { Atlantic }\end{array}$ \\
\hline Tuna, Yellowfin & $-t$ & All other stocks & $-t$ \\
\hline
\end{tabular}

MSC, Marine Stewardship Council.

†No sustainable source identified.

the world ${ }^{(11)}$ and $\mathrm{EU}^{(12)}$ are currently either fully exploited or over-exploited. For consumers, balancing health motivation with concerns over sustainability can present a dilemma, particularly as very little guidance is available.

The second report of the Council of Food Policy Advisors (specifically entrusted with the task of making policy recommendations for sustainable production and consumption of food) highlights fish consumption as a core issue and recommends shifting targets for consumption towards produce that has come from only sustainably managed stocks, eliminating the consumption of threatened species ${ }^{(13)}$. Although the problem has been highlighted, it has not yet been communicated effectively to the public. Although the FSA has acknowledged the need to raise consumers' awareness of the type of fish consumed ${ }^{(14)}$, and indeed recently updated its consumer guidelines for fish consumption to incorporate some information on sustainability and help consumers choose appropriate types of fish ${ }^{(15)}$, the primary message for consumers to increase fish consumption remains unchanged. Moreover, its recommendations still include several types of fish that the UK Marine Conservation Society (MCS) believes are the most vulnerable to over-fishing and/or are fished using methods that damage the environment ${ }^{(16)}$. In an effort to aid consumers, the Marine Stewardship Council (MSC), the world's leading certification and eco-labelling programme for sustainable seafood, uses its eco-label to communicate whether a fish or fish product is from a sustainable source $^{(17)}$. In addition, the MCS provides a 'pocket guide' to consumers ${ }^{(16)}$ listing fish from sustainable sources and those to be avoided. Sustain ${ }^{(18)}$, the alliance for better food and farming, reports only five types of fish that can be recommended to the consumer wishing to purchase for health and sustainability reasons. Communicating the complex information to consumers about choosing fish from sustainable sources is, however, challenging (Table 1).

It is clear that consumption of fish and fish products has a considerable impact on human nutrition, on the marine environment and on the long-term viability of fish stocks, but very little guidance is available to consumers when making purchasing decisions. Therefore, the present study sought to determine whether health and/or sustainability were motivating factors in terms of purchasing and consuming fish. In addition, the study aimed to examine the extent to which consumers were concerned about where the fish they purchased came from and whether they regularly purchased fish certified as sustainable by the MSC. Finally, the study aimed to investigate sociodemographic trends in the purchase of MSC fish, as well as attitudes towards fish purchase and consumption.

\section{Methods}

\section{Design and sample}

Nottinghamshire is situated in the East Midlands region, and this was selected as a useful study site as it offers a representative sample of the UK in terms of climate and geography ${ }^{(19)}$. In addition, data from the most recent Family Food Survey show that the population of East Midlands consumes an average of $1 \cdot 15$ portions of fish per week, which is close to the national average ${ }^{(20)}$. Self-administered questionnaires were mailed to 2500 Nottinghamshire residents, accompanied by an invitation letter, an information sheet and a freepost return envelope. Potential participants were randomly selected from five electoral registers encompassing both urban and rural areas (Nottingham City, Broxtowe, Rushcliffe, Gedling and Erewash). All non-responders were followed up with reminders after two weeks. All responses were anonymous and no incentive was provided.

\section{Measures}

\section{Attitudes}

Attitudinal items were created from thematic categories that were derived from qualitative interviews conducted by the authors with eleven Nottinghamshire adults (A Clonan, JA Swift, M Holdsworth et al., unpublished results). The interview schedule used in the qualitative interviews was structured around the consumer guidelines 
Table 2 Participants' attitudes towards fish purchase/consumption

\begin{tabular}{|c|c|c|c|c|c|c|}
\hline \multirow[b]{2}{*}{ Attitudinal item } & \multicolumn{2}{|c|}{ Strongly agree/agree } & \multicolumn{2}{|c|}{ Neither agree/disagree } & \multicolumn{2}{|c|}{ Disagree/strongly disagree } \\
\hline & $n$ & $\%$ & $n$ & $\%$ & $n$ & $\%$ \\
\hline I buy fish mainly for the health benefits & 425 & $57 \cdot 0$ & 182 & $24 \cdot 4$ & 138 & $18 \cdot 5$ \\
\hline $\begin{array}{l}\text { I am confused about which type of fish I should eat for } \\
\text { health reasons }\end{array}$ & 131 & $18 \cdot 5$ & 172 & $24 \cdot 2$ & 407 & $57 \cdot 3$ \\
\hline I do not usually check where the fish has come from & 336 & $46 \cdot 0$ & 182 & $24 \cdot 9$ & 212 & $29 \cdot 0$ \\
\hline $\begin{array}{l}\text { I am confused about which type of fish I should be eating } \\
\text { to protect fish stocks }\end{array}$ & 333 & $46 \cdot 1$ & 184 & $25 \cdot 4$ & 206 & $28 \cdot 5$ \\
\hline I am not sure whether to buy farmed fish & 272 & $38 \cdot 4$ & 268 & $37 \cdot 8$ & 169 & $23 \cdot 8$ \\
\hline $\begin{array}{l}\text { I always check that the fish I am buying has come from } \\
\text { a sustainable source }\end{array}$ & 193 & $26 \cdot 8$ & 262 & $36 \cdot 4$ & 265 & $36 \cdot 8$ \\
\hline
\end{tabular}

for sustainable food provided by Sustain ${ }^{(21)}$, as it provides the best possible working definition for consumers that is currently available in the UK. Items were designed using the guiding principles outlined by Oppenheim ${ }^{(22)}$; for example, some items were worded positively and some negatively to avoid acquiescence response bias. The questionnaire was piloted using a sample consisting of forty-two women and thirty-eight men, recruited using opportunistic sampling. Frequency analysis was conducted on the pilot data and several statements were either removed or replaced because of their poor discriminative properties. The final attitudinal section consisted of seventy-two items covering a variety of sustainabilityrelated issues that consumers are confronted with at the time of purchase (e.g. animal welfare, local food and organic food). Readers are invited to contact the corresponding author for a full copy of the questionnaire used. Six of these items related to fish purchase and consumption (Table 2). A 5-point Likert scale was used to assess attitudinal statements, with the scale ranging from 'strongly agree' to 'strongly disagree'; participants were also able to state that the item was 'not applicable' to account for non-fish eaters and to reduce false reporting. To simplify analysis, responses to the attitudinal variables were categorized into 'agree' (combined responses for 'strongly agree' and 'agree'), 'neither agree nor disagree' and 'disagree' (combined responses for 'strongly disagree' and 'disagree'). The six items about fish purchase and consumption produced a Cronbach's $\alpha$ coefficient of $0 \cdot 60$, indicating that the construct was internally consistent and therefore reliable ${ }^{(23)}$. In addition, the six items produced a good spread of responses (Table 2) establishing their face validity ${ }^{(22)}$. The scale was also assessed for readability using the Flesch-Kincaid Reading Grade Level ${ }^{(24)}$ and achieved a score of $3 \cdot 8$, indicating that it was suitable reading material for 10-11-year-olds and therefore acceptable for use in a general UK population.

\section{Purchasing behaviour}

Participants were asked to indicate how frequently they purchased a range of categories of 'sustainable food'. For fish, participants were asked to choose whether they purchased MSC-approved fish using a 4-point frequency scale 'always', 'often', 'sometimes' or 'never'. Participants were also asked to indicate whether in the past 12 months they had purchased MSC fish 'more often', 'less often' or whether there was 'no change', when compared with the previous year.

\section{$F F Q$}

A semi-quantitative FFQ was developed on the basis of the five food groups defined in the UK's Eatwell plate ${ }^{(25)}$. Participants were asked to choose how frequently they consumed fish on a scale from 'never' to 'twice a day or more'. Standard food portion sizes were included on the basis of national food portion sizes, which for fish was ' 1 average fillet', together with an image depicting one portion size. Daily intakes were calculated using this information.

\section{Sociodemographic characteristics}

Socio-economic and sociodemographic data were collected at both individual (gender, age, educational level and profession) and household levels (urban/rural, household income). Age groups were created by dividing participants into four groups on the basis of a life-stage approach: 18-30, 31-45, 46-60 and 61-91 years. Using multiple correspondence analyses (MCA), a socio-economic score was created that ranked participants using four demographic variables: educational level, occupation, household income and individual food expenditure (calculated by household food expenditure/number of people in the household). MCA is a multivariate statistical technique used to reduce the number of variables in a data set to a smaller number of dimensions and has been previously validated and used in the nutritional field ${ }^{(26-28)}$. The socio-economic score produced a Cronbach's $\alpha$ coefficient of $0 \cdot 7$, indicating reliability ${ }^{(23)}$. Participants were then ranked and divided into three groups - higher, medium and lower socio-economic status - each tertile representing one-third of the sample.

\section{Data analysis}

Data were entered into the Statistical Package for the Social Sciences statistical software package version $16 \cdot 0$ 
(SPSS Inc., Chicago, IL, USA) using EpiData software version 3.1 (EpiData Association, Odense, Denmark) ${ }^{(29)}$. An intra-rater reliability check was conducted on a random $10 \%$ sample of questionnaires, which revealed an error rate of $<1 \%{ }^{(30)}$. Categorical data were analysed using the $\chi^{2}$ test, followed by the adjusted $\chi^{2}$ test to ensure that observed differences were not due to confounding variables of gender, age group or socio-economic group. Significance was taken as $P<0 \cdot 05$.

\section{Etbical considerations}

The present study received approval from the Nottingham University Ethics Committee. Participants were considered to have given their consent to participate in the study if they completed and returned the questionnaire.

\section{Results}

\section{Response rate}

Of the 2500 individuals invited to participate in the present study, 842 usable responses were received and, following adjustment for people who had moved or died, a

Table 3 Sociodemographic characteristics of participants

\begin{tabular}{lll}
\hline & $n$ & $\%$ \\
\hline Gender & & \\
Male & 333 & $40 \cdot 1$ \\
Female & 497 & $59 \cdot 9$ \\
Age (years) & & \\
$18-30$ & 101 & $12 \cdot 2$ \\
$31-45$ & 185 & $22 \cdot 4$ \\
$46-60$ & 262 & $31 \cdot 8$ \\
$61-91$ & 277 & $33 \cdot 6$ \\
Socio-economic group & & \\
Higher & 280 & $33 \cdot 3$ \\
Medium & 280 & $33 \cdot 3$ \\
Lower & 282 & $33 \cdot 5$ \\
\hline
\end{tabular}

response rate of $35 \cdot 6 \%$ was achieved. Within the sample of 842 usable responses, participants ranged in age from 18 to 91 years, the majority of whom were in the two oldest age groups $(31 \cdot 8 \%$ aged $46-60$ years; $33 \cdot 6 \%$ aged $\geq 61$ years; Table 3$)$. Just under two-thirds of the sample were women ( $n$ 497, 59.9\%; Table 3).

\section{Dietary intake}

Participants consumed an average of 1.4 portions of fish per week. Overall, $31.7 \%$ of participants consumed two or more portions of fish per week, but over two-thirds $(68 \cdot 3 \%)$ did not meet the recommendation of two portions per week; in addition, $6 \cdot 2 \%$ reported 'never' consuming fish. Women were significantly $\left(\chi_{(1)}^{2}=4 \cdot 28 ; P<0 \cdot 05\right)$ more likely than men to meet this recommendation, as were participants in the oldest age group $\left(\chi_{(3)}^{2}=10.58 ; P<0 \cdot 05\right.$; Table 4). These effects persisted when adjusted for age, gender and socio-economic group (Table 4). In addition, participants ranked in the highest socio-economic group were more likely to meet the required intake $\left(\chi_{(2)}^{2}=5 \cdot 75\right.$; $P<0 \cdot 05)$, although this effect was diminished when the data were adjusted for gender and age (Table 4).

\section{Attitudes to fisb}

More than half of the participants (57.0\%; Table 2$)$ agreed that they purchased fish 'mainly for the health benefits' and a similar proportion disagreed with the statement 'I am confused about which type of fish I should eat for health reasons' (57.3\%; Table 2). Those participants agreeing that they bought fish 'mainly for the health benefits' were significantly more likely to meet the dietary recommendations for fish consumption $\left(\chi_{(2)}^{2}=17 \cdot 55\right.$; $P<0 \cdot 001)$, as were those disagreeing that they were 'confused about which type of fish I should eat for health reasons' $\left(\chi_{(2)}^{2}=15 \cdot 17 ; P<0 \cdot 001\right)$. Just over a quarter of participants (29.0\%; Table 2$)$ disagreed that they 'don't usually check where the fish has come from', whereas a

Table 4 Relationship between fish consumption and sociodemographic profile

\begin{tabular}{|c|c|c|c|c|c|c|c|}
\hline & \multicolumn{2}{|c|}{$\begin{array}{c}\text { Consuming two or more } \\
\text { portions per week } \\
(140 \mathrm{~g}=\text { one portion })\end{array}$} & \multicolumn{2}{|c|}{$\begin{array}{c}\text { Consuming less than two } \\
\text { portions per week } \\
(140 \mathrm{~g}=\text { one portion })\end{array}$} & \multirow{2}{*}{$\begin{array}{l}\text { Mean weekly } \\
\text { consumption } \\
\text { (number of } \\
\text { portions) }\end{array}$} & \multirow[b]{2}{*}{$\chi^{2}$} & \multirow[b]{2}{*}{ Adjusted $\chi^{2}+$} \\
\hline & $n$ & $\%$ & $n$ & $\%$ & & & \\
\hline \multicolumn{8}{|l|}{ Gender } \\
\hline Male & 90 & $27 \cdot 2$ & 241 & $72 \cdot 8$ & $1 \cdot 42$ & $4 \cdot 28^{*}$ & $5 \cdot 08^{*}$ \\
\hline Female & 168 & $34 \cdot 0$ & 326 & $66 \cdot 0$ & $1 \cdot 63$ & & \\
\hline \multicolumn{8}{|c|}{ Age group (years) } \\
\hline $18-30$ & 31 & $30 \cdot 7$ & 70 & $69 \cdot 3$ & $1 \cdot 25$ & $10 \cdot 54^{*}$ & $10 \cdot 48^{*}$ \\
\hline $31-45$ & 43 & $23 \cdot 2$ & 142 & $76 \cdot 8$ & $1 \cdot 2$ & & \\
\hline $46-60$ & 80 & $30 \cdot 5$ & 182 & $69 \cdot 5$ & $1 \cdot 53$ & & \\
\hline 61-91 & 102 & $37 \cdot 5$ & 170 & $62 \cdot 5$ & $1 \cdot 82$ & & \\
\hline \multicolumn{8}{|c|}{ Socio-economic group } \\
\hline Lower & 75 & $28 \cdot 4$ & 204 & $73 \cdot 1$ & $1 \cdot 35$ & $5 \cdot 75^{\star}$ & $-4 \cdot 1$ \\
\hline Middle & 89 & $33 \cdot 7$ & 191 & $68 \cdot 2$ & $1 \cdot 52$ & & \\
\hline Higher & 100 & $36 \cdot 4$ & 175 & $63 \cdot 6$ & $1 \cdot 85$ & & \\
\hline
\end{tabular}

${ }^{\star} P<0.05$.

tAdjusted for gender, age and socio-economic group. 
Table 5 Relationship between attitude towards fish and sociodemographic profile

\begin{tabular}{|c|c|c|c|c|c|c|}
\hline \multirow[b]{2}{*}{ Attitudinal item } & \multicolumn{2}{|c|}{ Gender } & \multicolumn{2}{|c|}{ Age group } & \multicolumn{2}{|c|}{ Socio-economic group } \\
\hline & $\chi^{2}$ & Adjusted $\chi^{2} \dagger$ & $\chi^{2}$ & Adjusted $\chi^{2}+$ & $\chi^{2}$ & Adjusted $\chi^{2}+$ \\
\hline I buy fish mainly for the health benefits & $3 \cdot 62$ & $6 \cdot 44$ & $40 \cdot 53^{\star \star *}$ & $51 \cdot 49^{\star \star \star}$ & $6 \cdot 73$ & $9 \cdot 31$ \\
\hline $\begin{array}{l}\text { I am confused about which type of fish I should eat } \\
\text { for health reasons }\end{array}$ & $0 \cdot 16$ & $0 \cdot 29$ & $8 \cdot 44$ & $12 \cdot 89$ & $8 \cdot 38$ & $9 \cdot 83$ \\
\hline I do not usually check where the fish has come from & $5 \cdot 56$ & $5 \cdot 95$ & $5 \cdot 74$ & $16 \cdot 44$ & $3 \cdot 23$ & $12 \cdot 92$ \\
\hline $\begin{array}{l}\text { I am confused about which type of fish I should be } \\
\text { eating to protect fish stocks }\end{array}$ & $8 \cdot 66^{*}$ & $9 \cdot 10$ & $10 \cdot 99$ & $14 \cdot 43$ & $2 \cdot 76$ & $5 \cdot 29$ \\
\hline I am not sure whether to buy farmed fish & $17 \cdot 65^{\star \star *}$ & $18 \cdot 78^{\star *}$ & 8.53 & $11 \cdot 08$ & $5 \cdot 73$ & $4 \cdot 83$ \\
\hline $\begin{array}{l}\text { I always check that the fish I am buying has come from } \\
\text { a sustainable source }\end{array}$ & $3 \cdot 47$ & $4 \cdot 22$ & $17 \cdot 89^{\star \star}$ & $27 \cdot 93^{\star \star}$ & $4 \cdot 42$ & $12 \cdot 94$ \\
\hline
\end{tabular}

${ }^{\star} P<0.05,{ }^{\star \star} P<0.01,{ }^{\star \star *} P<0.001$.

tAdjusted for gender, age group and socio-economic group.

similar proportion reported that they 'always check that the fish I'm buying has come from a sustainable source' (26.8\%; Table 2). In addition, more than a quarter of the participants were 'confused about which type of fish I should be eating to protect fish stocks' (28.5\%; Table 2) and over one-third (38.4\%; Table 2) agreed that they were 'not sure whether to buy farmed fish'.

Participants from the oldest age group (61-91 years) were more likely to agree that they 'buy fish mainly for the health benefits' $\left(\chi_{(6)}^{2}=40.53 ; P<0.001\right)$ and also more likely to 'check that the fish I'm buying has come from a sustainable source' $\left(\chi_{(6)}^{2}=17 \cdot 89 ; P<0 \cdot 01\right)$, compared with the youngest age group (Table 5). No significant age effects were observed for the other attitudinal items. Women were also more likely to agree that they were 'not sure whether to buy farmed fish' $\left(\chi_{(2)}^{2}=17 \cdot 65\right.$; $P<0 \cdot 001)$. No significant effects were observed between gender and socio-economic group for the other attitudinal items.

\section{Purchasing data}

Less than $10 \%$ of participants reported purchasing MSClabelled fish 'always' or 'often', whereas the majority (75\%) of participants declared 'never' purchasing MSC-labelled fish. No significant relationship between purchasing of MSC-labelled fish and gender, age or socio-economic group was observed.

Participants were significantly more likely to buy MSClabelled fish regularly if they agreed with the statement 'I always check that the fish I'm buying comes from a sustainable source' $\left(\chi_{(4)}^{2}=26 \cdot 31 ; P<0 \cdot 001\right)$. Similarly, participants were significantly more likely to buy MSClabelled fish regularly if they disagreed with the statement 'I don't usually check where the fish has come from' (i.e. implicitly suggesting that they do check) $\left(\chi_{(4)}^{2}=18 \cdot 45\right.$; $P<0 \cdot 001)$. In addition, those participants were significantly less likely to buy MSC-labelled fish if they agreed with the statements 'I am confused about which type of fish I should be eating to protect fish stocks' $\left(\chi_{(4)}^{2}=21.34 ; P<0 \cdot 001\right)$ and 'I am not sure whether to buy farmed fish' $\left(\chi_{(4)}^{2}=23 \cdot 12 ; P<0 \cdot 001\right)$.

\section{Discussion}

Just over half of the participants in the present study reported that they buy fish mainly for health reasons, indicating that health is important for some, particularly older, consumers - a finding that concurs with previous research ${ }^{(31-34)}$. As a consequence, just under half of the participants disagreed that they bought fish mainly for health reasons and approximately one-fifth (18.5\%) reported being confused about which type of fish to eat for health reasons. Interestingly, those participants who were meeting the recommended consumption were significantly more likely to be the ones who also agreed that they 'buy fish mainly for health' and were not confused about health issues. Therefore, although some participants have heeded the public health nutrition message, a considerable proportion of participants have not necessarily followed up on the health benefits associated with fish consumption. This strongly suggests that further health promotion in this area is required, an assertion that is further justified by the positive relationship between achieving the dietary recommendations of fish and beliefs about the health benefits of fish consumption found by the present study. Having said this, it has been estimated that if all consumers were to increase intake in order to meet the FSA's recommendation for fish intake of two $140 \mathrm{~g}$ portions per week, then supply in the UK would also have to be increased by $40 \%{ }^{(35)}$. Increasing supply is, however, problematic as the marine ecosystem is already being exploited to such an extent that it is projected that worldwide fish stocks will be depleted by $2050^{(36)}$.

Although the public health nutrition message seems to have been taken on board by some UK consumers, there appears to be less awareness regarding sustainability issues when purchasing fish. Just over a quarter of the participants responded in a way that indicated that they usually check where their fish has come from, whereas a similar proportion indicated that they were not confused about which type of fish they should be eating to protect fish stocks (i.e. strongly disagree or disagree with negatively worded statements). Farmed fish represented a further source of 
confusion for a considerable number of participants, and this also requires clarification to enable consumers to make an informed choice. Low awareness levels are problematic as they are shown here to be associated with negative purchasing behaviour, and the reported purchasing of MSC fish in the present study was minimal.

\section{Strengths and limitations}

Much consideration was given to the construction of the questionnaire, particularly with regard to the issues of reliability and validity that were addressed during the development stage and that improved following piloting. Strategies were used to optimize the response rate ${ }^{(37)}$, which, following adjustment, was $35.6 \%$, with the female/oldest age group over-represented and the male/ youngest age group under-represented, which is comparable to similar research conducted ${ }^{(38)}$ and is favourable when considering the length of the questionnaire (twelve pages). Of the 2500 questionnaires sent out, a total of 842 were returned completed; as the sample was randomly selected the sociodemographic characteristics of non-responders remained unknown, which may have influenced the resulting data ${ }^{(39)}$. Further limitations include space available in the questionnaire, particularly in the food-frequency section where the ideal would have discriminated between different types of fish consumed; however, as the questionnaire was self-completed, conciseness was paramount. Therefore, data on fish intake refer to total fish consumed and do not discriminate between canned and fresh fish. In addition, the FFQ has not been tested against any other measure for validity as its main purpose was to rank individuals' intakes relative to each other within the sample, rather than be a measure of absolute intake. As the questionnaire was selfcompleted, other potential biases included the inability to verify whether participants had understood questions correctly and missing data from non-response. To counter these potential sources of bias, the questionnaire was piloted during its development to ensure that ambiguous questions were removed. Its subsequent simplicity was verified by its readability level that indicated that it was suitable reading material for 10-11-year-olds and therefore acceptable for use in a general UK population. Respondents with missing data were automatically excluded from the analysis for the overall scale; thus, this potential bias was accounted for.

Cronbach's $\alpha$ measuring internal consistency of the fish attitudinal scale was lower than what one would expect from a homogeneous scale that encompassed only one concept. However, this scale included attitudes towards health and sustainability of fish and hence $\alpha$ measured the coherence of these two combined concepts. Consequently, although the items were related and showed good internal consistency ${ }^{(40)}$, the resulting $\alpha$ might be expected to be lower than that of a scale testing only one homogeneous concept. Cronbach's $\alpha$ is also proportional to the number of items on a scale; hence, a scale of six items with an $\alpha$ of 0.6 is still acceptable.

\section{Conclusions}

The basis of the evidence that underpins current FSA recommendations for fish consumption (based on the Scientific Advisory Committee on Nutrition and the Committee on Toxicity report ${ }^{(2)}$ ) has recently been called into question $^{(41)}$. Further research is needed to assess whether two $140 \mathrm{~g}$ portions of fish (of which one should be oily) provides significant beneficial effects for all population groups ${ }^{(41)}$. In the meantime, although the FSA may address the need for clearer information on the proposed 'integrated food advice and information for consumers', which will work alongside other UK Government departments after its launch in early $2011^{(13)}$, at present there are more UK consumers stating that they buy fish for personal health reasons than there are stating that they buy after considering environmentally sustainable choices. It may be theoretically possible to do both $^{(41)}$, but scant guidelines are currently available to guide consumers. Data shown in the present study have demonstrated that there is not only a lack of awareness but also confusion, which is important as these factors were shown to be associated with low purchase of MSC-certified fish.

\section{Implications for practice}

One possible solution for the consumer's dilemma is 'choice editing', whereby retailers sell only sustainably sourced fish ${ }^{(42)}$. At present, this option has been fully implemented by only one UK retailer ${ }^{(43)}$ as others who initially pledged to sell only MSC-certified fish relinquished this goal after realizing that supply could not match demand ${ }^{(44)}$. Action also needs to be taken at a food policy level to tackle the environmental impact of the food supply ${ }^{(45)}$ so that the onus does not fall on the consumer to deal with such a pressing issue alone. The Sustainable Development Commission made some recommendations to the government in its recent report 'Setting the Table', which included promotion of sustainable fish by a celebrity chef, expansion of the MSC accreditation scheme and development of herbivore aquaculture $^{(46)}$. The report also suggested changing dietary guidelines to recommend eating less fish, and pointed out that public health problems resulting from a lack of fish will be worse in the long term if stocks deplete as estimates have predicted $^{(46)}$. All these suggestions require further consideration as it is likely that policy makers will have to implement a combination of measures to start addressing this issue.

Health promotion could be used to provide clearer messages to the public to support wider policy changes. Recommendation of only those species of fish certified as sustainable needs to be made in a plain and simple manner, and promotion of other sustainable sources of LCPUFA, such as algae ${ }^{(41)}$, should be considered. The latter 
may mean revising current recommendations for fish intake, which have been described as unethical by some ${ }^{(47)}$. Public health nutritionists and dietitians need to play a key role in communicating in simple terms to the general public how nutritional needs can be met while protecting fish stocks. As recently stated by Sulda et $a l^{(48)}$ ' ....nutritionists have a responsibility to promote a food supply that is not only nutritious, but also sustainable' (p. 305).

\section{Acknowledgements}

The present study was funded by the University of Nottingham. The authors have no conflict of interest to declare. A.C., M.H, J.A.S. and P.W. designed the project; A.C. analysed and interpreted the data with statistical input from D.L., M.H. and J.A.S.; A.C. drafted the article and M.H, J.A.S., D.L. and P.W. reviewed it critically for important intellectual content. All authors approved the final version to be published. The authors thank all participants for taking time to complete the questionnaire.

\section{References}

1. Food Standards Agency (2004) Oily fish advice: your questions answered. http://food.gov.uk.multimedia/faq/ oilyfishfaq/ (accessed September 2009).

2. Scientific Advisory Committee on Nutrition, Committee on Toxicity (2004). Advice on Fish Consumption: Benefits and Risks. London: The Stationery Office.

3. Terry PD, Rohan TE \& Wolk A (2003) Intakes of fish and marine fatty acids and the risks of cancers of the breast and prostate and of other hormone related cancers: a review of the epidemiological evidence. Am J Clin Nutr 77, 532-543.

4. The Vegetarian Society (2009) Information sheet - omega 3. http://www.vegsoc.org/info/omega3.html (accessed October 2009).

5. Penny MEK, Harris WS \& Appel LJ (2002) Fish consumption, fish oil, omega-3 fatty acids, and cardiovascular disease. Circulation 106, 2747-2757.

6. Brunner EJ, Jones PJS, Friel S et al. (2009) Fish, human health and marine ecosystem health: policies in collision. Int J Epidemiol 38, 93-100.

7. World Cancer Research Fund/American Institute for Cancer Research (2007) Food, Nutrition, Physical Activity and the Prevention of Cancer: A Global Perspective. Washington, DC: AICR.

8. Food Standards Agency (2010) Fish and shellfish. http:// www.eatwell.gov.uk/healthydiet/nutritionessentials/fishand shellfish/ (accessed October 2009).

9. Food Standards Agency (2010) National Diet Nutrition Survey: headline results from year 1. http://www.food.gov. uk/science/dietarysurveys/ndnsdocuments/ndns0809year1 (accessed June 2010).

10. Department for the Environment, Food and Rural Affairs (2009) Fish stocks: Common Fisheries Policy (CFP) Reform. http://www.defra.gov.uk/foodfarm/fisheries/policy/cfp/ cfp-reform.html (accessed October 2009).

11. Food and Agriculture Organization of the United Nations (2006) The State of World Fisheries and Aquaculture. Rome: United Nations.

12. Thurstan RH, Brocklington S \& Roberts CM (2010) The effects of 118 years of industrial fishing on UK bottom trawl fisheries. Nat Commun 1, 15.
13. Department for the Environment, Food and Rural Affairs (2010) Food: a recipe for a healthy, sustainable and successful future. Second Report of the Council of Food Policy Advisors. http://www.defra.gov.uk/foodfarm/food/policy/council/pdf/ cfpa-rpt-100315.pdf (accessed November 2009).

14. Food Standards Agency (2009) Review of agency's advice on fish consumption. http://www.food.gov.uk/consultations/ consulteng/2009/advicefishconsumption (accessed June 2009).

15. Food Standards Agency (2009) Agency's fish advice takes account of sustainability. http://www.food.gov.uk/news/ newsarchive/2009/sep/fish (accessed October 2009).

16. Marine Conservation Society (2008) Fish Online: fish to avoid. http://www.fishonline.org/advice/avoid/ (accessed September 2009)

17. Marine Stewardship Council (2009) What we do. http:// www.msc.org/about-us/what-we-do (accessed September 2009).

18. Sustain (2005) Like shooting fish in a barrel. http://www. sustainweb.org/foodfacts/like_shooting_fish_in_a_barrel/ (accessed October 2009).

19. Pettinger C (2004) A comparison of the influences on food choice in Southern France and Central England. PhD Thesis, University of Nottingham.

20. Department for the Environment, Food and Rural Affairs (2008) Family Food. London: The Stationery Office.

21. Sustain (2009) Consumer guide to sustainable food. http:// www.sustainweb.org/sustainablefood/ (accessed September 2009).

22. Oppenheim AN (2005) Questionnaire Design, Interviewing and Attitude Measurement. London: Continuum.

23. Bowling A (2002) Research Methods in Health: Investigating Health and Health Services, 2nd ed. Buckingham: Open University Press.

24. Kincaid JP, Fishburne RP, Rogers RL et al. (1975) Derivation of New Readability Formulas (Automated Readability Index, Fog Count and Flesch Reading Ease Formula) for Navy Enlisted Personnel. Memphis, TN: Naval Air Station.

25. Food Standards Agency (2008) The Eatwell plate. http://www. food.gov.uk/multimedia/pdfs/publication/eatwellplate0210.pdf (accessed September 2009).

26. Holdsworth M, Gartner A, Landais E et al. (2004) Perceptions of healthy and desirable body size in urban Senegalese women. Int J Obes (Lond) 28, 1561-1568.

27. Vyas S \& Kumaranayake L (2006) Constructing socioeconomic status indices: how to use principal components analysis. Health Policy Plan 21, 459-468.

28. Leibovici DG (2010) Spatio-temporal multiway decomposition using principal tensor analysis on k-modes: the $\mathrm{R}$ package PTAk. J Statist Softw 34, 1-34.

29. Lauritsen JM, Bruus L \& Myatt M (2000) EpiData: A Tool for Validated Data Entry and Documentation of Data. Denmark: Brixton Health.

30. Meeuwisse WH, Hagel BE \& Fick GH (1999) The impact of single versus dual data entry on accuracy of relational database information. I Inform Primary Care June issue, $2-8$.

31. Olsen SO (2001) Consumer involvement in seafood as family meals in Norway: an application of the expectancyvalue approach. Appetite 36, 173-186.

32. Gempesaw CM, Bacon JR, Wessells CR et al. (1995) Consumer perceptions of acquaculture products. Am J Agric Econ 77, 1306-1312.

33. Olsen SO (2003) Understanding the relationship between age and seafood consumption: the mediating role of attitude, health involvement and convenience. Food Qual Prefer 14, 199-209.

34. Verbeke W \& Vackier I (2005) Individual determinants of fish consumption: application of the theory of planned behaviour. Appetite 44, 67-82. 
35. The Royal Commission on Environmental Pollution (2004) Turning the tide: addressing the impact of fisheries on the marine environment. http://www.rcep.org.uk/reports/25marine/documents/Turningthetide.pdf (accessed February 2011).

36. Worm B, Barbier EB, Beaumont $\mathrm{N}$ et al. (2006) Impacts of biodiversity loss on ocean ecosystem services. Science $\mathbf{3 1 4}$, 787-790.

37. Edwards P, Roberts I, Clarke M et al. (2002) Increasing response rates to postal questionnaires: systematic review. BMJ 324, 1183.

38. Pettinger $\mathrm{CH}$, Holdsworth $\mathrm{M}$ \& Gerber M (2006) Meal patterns and cooking practices in Southern France and Central England. Public Health Nutr 9, 1020-1026.

39. Kotaniemi JT, Hassi J, Kataja M et al. (2001) Does nonresponder bias have a significant effect on the results in a postal questionnaire study? Eur J Epidemiol 17, 809-817.

40. Streiner DL \& Norman GR (2008) Health Measurement Scales: A Practical Guide to their Development and Use. Oxford: Oxford University Press.

41. National Heart Forum (2009) Fish: dietary advice and dwindling marine stocks - How do we manage the policy conflicts? Members Meeting 11 September 2009. http://nhfshare. heartforum.org.uk/RMAssets/NHFMeetingnotes/2009/Fish, $\% 20$ sustainability $\% 20 \& \% 20$ CHD $\% 20$ prevention $\% 20-\% 20$ Summary\%20note_Sep\%2009.pdf (accessed February 2011).
42. Sustainable Development Commission (2009) Sustainable Development Commission's response to the Review of Food Standard Agency's advice on fish consumption. http://www.sd-commission.org.uk/publications/downloads/ SDCResponse_FSAReviewFishConsumption_Final.pdf (accessed October 2009).

43. Marks and Spencers (2009) Plan A: sustainable raw materials; fish. http://plana.marksandspencer.com/we-aredoing/sustainable-raw-materials/progress (accessed October 2009).

44. Natural England (2009) Sea fisheries: steps to sustainability. http://www.naturalengland.org.uk/Images/SeaFisheriesReport_ tcm6-13325.pdf (accessed October 2009).

45. Caraher M \& Coveney J (2004) Public health nutrition and food policy. Public Health Nutr 7, 591-598.

46. Sustainable Development Commission (2009) Setting the table: advice to government on priority elements of sustainable diets. http://www.sd-commission.org.uk/publications/ downloads/Setting_the_Table.pdf (accessed July 2010).

47. Bere E \& Brug J (2008) Towards health-promoting and environmentally friendly regional diets - a Nordic example. Public Health Nutr 12, 91-96.

48. Sulda H, Coveney J \& Bentley M (2009) An investigation of the ways in which public health nutrition policy and practices can address climate change. Public Health Nutr 13, 304-313. 